Çukurova Üniversitesi Mühendislik Mimarlık Fakültesi Dergisi, 28(1), ss.,157-162, Aralık 2015

Çukurova University Journal of the Faculty of Engineering and Architecture, 28(1), pp.157-162, December 2015

\title{
Hata Türleri ve Etkileri Analizinin, HTEA, Tekstil Boya-Terbiye İşletmelerinde Kullanımı
}

\author{
Emel Ceyhun SABIR ${ }^{* 1}$, Mehmet BEBEKLi ${ }^{1}$ \\ ${ }^{1}$ Çukurova Üniversitesi, Mühendislik-Mimarlık Fakültesi, Tekstil Mühendisliği Bölümü, Adana
}

Geliş tarihi: $21.10 .2015 \quad$ Kabul tarihi:25.12.2015

\section{Özet}

Tekstil sektöründe, ürünlerin kalitesi ve süreçlerin güvenilirliği çok önemlidir. Kalite güvencesini tahmin için yöntemler hala çok yaygın değildir. HTEA (Hata Türleri ve Etkileri Analizi) analiz ve kalite güvencesi potansiyel arızaları ve hasarları önlemek için önemli bir teknik metottur. HTEA süreci analiz eder ve başarısızlıkları, kusurları önlemek amacıyla riskleri değerlendirir. Bu çalışmada tekstil boya terbiye işletmesine HTEA tekniği uygulanmıştır. Çalışma sonucunda işletmede risk önceliği olan üç hata/kusur türü tespit edilmiştir ve önleyici faaliyetlere karar verilebilmiştir

Anahtar Kelimeler: HTEA, Tekstil, Boya Terbiye, Kalite, Süreç güvenilirliği

\section{The Using of Failure Mode and Effects Analysis, FMEA in the Textile Dyeing Finishing Mills}

\begin{abstract}
In the textile industry, quality of products and reliability of processes are very important. The methods for estimation of quality assurance still is not common. The FMEA (Failure Mode and Effect Analysis) is an important techical method to prevent potentialt failures and defects in quality assurance. Realibility of products and processes is improve the development and the production procedure. In this study, HTEA technique was applied to a selected textile dyeing finishing mill. At the result of the study, three risky failures/defects was found in the mill and the decision has been given to prevention activities
\end{abstract}

Keywords: FMEA, Textile, Dyeing Finishing, Quality, Realibility of Process

Yazışmaların yapılacağı yazar: Emel Ceyhun SABIR, Ç.Ü., Mühendislik Fakültesi, Tekstil Mühendisliği Bölümü, Adana, emelc@cu.edu.tr 


\section{GíRIŞ}

Tekstil işletmeleri; yapay lif, iplik, dokuma, örme ve terbiye teknolojilerinin yanı sıra, dokusuz yüzey ve teknik tekstil gibi ileri tekstil teknolojilerini de içeren geniş bir üretim alanıdır. Tekstil teknolojileri, moda ve hazırgiyim üretimi; hammaddeden mamule, karmaşık, pek çok dış etkenin üzerinde etkili olduğu uzun üretim hatlarına sahiptir. İmalat sanayiinin bu karmaşık yapılarında doğal olarak hatalarla karşılaşılır. Hataların bir kısmı üretim aşamasında yapılan kontrollerle giderilir. Buna rağmen tekstil hammaddesinin ürün aşamasına geldiğinde pek çok hata fark edilir. Bu aşamada mamulün hatalarının düzeltilmesi zordur ve ürün düşük kalite olarak sınıflandırılır. Hatalı ürün müşteriye teslim edilecek mal miktarında azalma anlamına geldiğinden eksik kısmın imalatının gerçekleşmesinden doğan termin (müşteriye teslim) süresinin uzaması problemini doğurur. Aynı zamanda da kazancın daha az olmasına neden olur. Tekstil işletmelerinde hataları ortaya çıkmadan yakalama çalışmaları, hataların mamul aşamasında fark edilmesi, nedeniyle büyük önem taşır. Hataları tespit etme eyleminde üretime kısa bir süre ara vermek gerekir. Kontroller yapıldıktan ve gerekirse düzeltici faaliyetlerden sonra üretime devam edilir.

Günümüzde hata türlerini tespit eden, hataları önemine göre derecelendiren ve hatayı önlemek için alınacak önlemleri tespit eden modern üretim yönetimi teknikleri bulunmaktadır. Problem çözmede ilk aşama, problemin doğru ve gerçekçi bir şekilde tanımlanmasıdır. Sonraki adım problemi yaratan nedenler belirlenerek analiz edilmesi ve son olarak çözüme yönelik adımların atılmasıdır. Problem çözme tekniklerinin tekstil sanayiine uygunluğu günümüzde pek çok çalışma ile ortaya konmuştur. Bu tekniklerden başlıcaları şunlardır: 6 Sigma, Beyin Fırtınası, Pareto Analizi, Kılçık diyagramı, PUKÖ, HTEA (Hata türleri ve etki analizleri).

Hata türleri ve etkileri analizi (HTEA) bir ürünün/prosesin hatalarını ve hataların etkilerini tespit eden metottur [1]. HTEA ile prosesin güvenilirliği kontrol altına alınır. Ürünlerin/prosesin güvenilirliği; müşteri tatminini sağlamakta çok etkilidir. Ürünlerin çeşitliliği arttığında, ürün karmaşık hale geldikçe, geleneksel tasarım yöntemleriyle düşük hata oranlarını elde edebilmek güçleşmektedir. HTEA, hatanın ortaya çıkması ile doğacak problemi ortaya koyarak riskleri tespit eder. Bu yönüyle analiz, önleyici faaliyetler alanına girmektedir. Başarılı bir Hata Türü ve Etki Analizi uygulaması; her hatanın nedenlerini ve etkenlerini belirler, potansiyel hataları tanımlar, hataların önceliğini ortaya çıkarır ve sorunların izlenmesini ve düzeltici faaliyetlerin yapılmasını sağlar [2].

HTEA tekniğinin tekstil ve konfeksiyon sektörlerinde uygulamalarına literatürde rastlanmaktadır. Yücel çalışmasında; HTEA yöntemini bir konfeksiyon işletmesinde uygulamıştır. İşletme içerisinde hata üreten faktörler belirlenmiştir. $\mathrm{Bu}$ faktörlerden dikim hatalarının giderilmesi, öncelikli giderilecek hata olarak kararlaştırılmıştır.

Dikim hatalarını gidermeye yönelik HTEA sistematiği uygulanmıştır. Uygulamanın sonuçları 12 haftalık üretim sürecinde izlenmiştir. İşletmenin jean pantolon üretim hattında $\% 4,1^{\prime}$ lik, gömlek üretim hattında ise \%5,2'lik bir dikim hatası azalması sağlanmıştır. Ayrıca, hata giderme zamanında ise 966,3 dakikalık bir kazanç elde edilmiştir [3]. Kaewsom ve Rojanarowan; direk polimer çekim prosesindeki kırı filament hatalarını azaltmak için HTEA tekniğini kullanmışlardır.

Çalışmada Hata Türleri ve Etkileri Analizi (HTEA) kusurun nedenlerini analiz etmek, iyileştirme yöntemlerini geliştirmek amaçlı kullanılmıştır. İyileştirme sonra, kırık filaman kusurlarında kusurlu oran1 \%3,35'den \%1,76'ya düşürülmüştür [4]. Özyazgan ve Engin; HTEA yöntemini örme sektöründe uygulamışlardır [5]. Gültekin; tekstil terbiyesinde pamuklu materyalin boyanmasında karşılaşılan hataların oluş nedenleri ve giderilme yöntemlerini incelemiştir [6]. Bu çalışmada, HTEA tekniği, tekstil boya terbiye işletmesine uygulanmıştır. 


\section{MATERYAL}

Bu çalışmada; Çukurova bölgesinde büyük ölçekli bir tekstil işletmesinin boya terbiye bölümünde yürütülmüştür. İşletme; yaklaşık $10000 \mathrm{~m}^{2}$ kapalı alanda yerleşik iplik boya ve kumaş boya terbiye fabrikasıdır. Dokuma fabrikalarından gelen iplik ve dokunmuş ham kumaşları, son teknolojik makinelerle işleyerek iplik boya ve kumaş boya apre işlemi yapmaktadır. Üretim kapasitesi 50.000 metre/gün olan tesislerde ayda 1.500 .000 metre üretim yapılabilmektedir.

\section{METOT}

Seçilmiş bir tekstil boya terbiye işletmesinde önleyici sistem aracı olarak, hata türü ve etki analizi (HTEA) tekniği uygulanmıştır. HTEA tekniği, genel olarak 4 farklı çeşidi vardır. Sistem HTEA' da amaç, işletmede etkinlik/performans faktörleri ile ekonomik faktörleri arasında uygun bir denge oluşturmaktır. Tasarım HTEA, üretime geçmeden önce uygulanır. Tasarımdaki hatalardan dolayı hizmet veya imalat aşamalarında ortaya çıkabilecek olası ürün hata türlerini inceler. Proses HTEA, üretim aşamalarını analiz eder. Proses yetersizliğinden doğan hataların türleri ve nedenlerini risklerini araştırır. Servis HTEA, müşteriye servis ulaşmadan analizi yapar. Böylece, servis hizmetini aksatacak ve gelişmesine engel olacak hata türleri ve riskler belirlenir, önleme faaliyetlerine karar verilir. HTEA tekniğinin öncelikli amaçları: potansiyel hataları önceden belirleyerek hataların oluşmasını önlemek, bir ürünün tasarım karakteristiklerini analiz ederek müşteri ihtiyaç ve beklentilerini karşıladığından emin olmak ve düzeltici önlemlerin sürekliliğini sağlamaktır.

HTEA, işletmelerde takım çalışması şeklinde yürütüldüğü zaman çok etkilidir. HTEA takımı; Hataların bulunması, Hataların risk önceliğinin saptanması, Hataları Düzeltici ve önleyici faaliyetlerin gerçekleştirilmesi ve Hatanın müşteriye ulaşmadan engellenmesi çalışmasını yapar. Hata türleri ve etkileri analizinin öğeleri; fonksiyonlar ve hata türleri, sonuçlar (etkiler), şiddet, nedenler, oluşum, kontrol, saptanabilirlik, risk öncelik sayısının belirlenmesidir. Bu öğeleri sağlayacak şekilde HTEA'nın aşamaları ortaya çıkar. HTEA aşamaları;

1. HTEA türüne karar vermek

2. HTEA yapılacak iş kapsamına karar vermek

3. İş kapsamında karşılaşılacak tüm hata türlerini tespit etmek.

4. Hatalara Şiddet (Hata Aralığı) Değeri Verilmesi

5. Hatalara Oluşma Olasılığının tespit edilmesi

6. Hatalara Saptanabilirlik Değerinin Verilmesi

7. Hataları önleyecek ve kontrol edecek önlemlerin tanımlanması,

8. Önerilen önlemlerin uygulamaya konulması ve etkilerinin değerlendirilmesi

9. Sonuçların belgelenmesi

Fonksiyonlar ve Hata türleri: Potansiyel hata türleri ya da hata kategorileri, başarısızlığın ne şekilde oluştuğunun açıklanması ile tanımlanabilmektedir. Hata türleri beş hata kategorisinden birine ait olabilir; tam hata, k1smi hata, aralıklı hata, zamanla oluşan hata, kullanımda ortaya çıkan hata.

Sonuçlar (Etkiler) : Hata türü oluştuğunda gerçekleşebilecek potansiyel sonuçları tanımlanır. Bu takımın yapacağı bir beyin firtınası faaliyetidir.

Şiddet : Hatanın müşteriye olan etkilerinin şiddetinin, 1 ile 10 derecesinde tahmin edilmesidir. Şiddet, hatanın oluştuktan sonra müşteriye göre ciddiyetini temsil eden bir faktördür. Müşteri hatayı görmeyecekse 1, müşteri önemsiz düzeyde rahatsız olacaksa 2 , hata müşteriyi rahatsız edecekse 4-6, hata müşteriyi aşırı rahatsız edecekse 7-8, müşterinin kabul edemeyeceği bir düzeydeyse bu hata için 9-10 şeklinde şiddet tayin edilir.

Nedenler : Ortaya çıkma olasılığı, bir hatanın oluşma ihtimali olup nedenler buna göre tanımlanır. Tanımlamaya şiddet değeri en büyük olan hata türlerinden başlamalıdır.

Oluşum : Takım çalışmasında hatanın oluşma olasılığına göre bir sıralama yapılır. Hatanın potansiyel sebebi ile karşılaşma olasılığı dikkate 
alınarak bu değer tahmin edilebilir. Tahmin yapılırken hatanın müşteriye ulaşmadan önce kontrol edilmediği varsayılır. Hatanın oluşma olasılığg zayıf ise 1 değeri verilir. İstatistiksel olarak kontrol altında bir süreçte düşük olasılıkla görülebilecek bir hata ise 2-5 arasında bir değer verilir. Ara sıra görülen ancak sürecin kontrol altında olduğu bir durumda ortaya çıkan hatalar için 6 değeri verilmektedir. Hatanın görülme olasılığı yüksek ise (örneğin $1 / 200$ ile $1 / 50$ arasında) bu değer 7-8 olacaktır. Hata, çok yüksek olasılıkla karşımıza çıkıyor ise (1/20 ile $1 / 5$ arasında) 9-10 değeri verilecektir.

Kontrol : HTEA tekniğinde kontroller amaçlarına göre sinıflandırılmaktadır:

Tip (1): Bu kontroller nedenin ya da hata türünün ortaya çıkışını engellemekte ya da ortaya çıkma olasılığını azaltmaktadır.

Tip (2): Bu kontroller neden ya da hata türünü belirlemekte ve düzeltici faaliyete yön vermektedir.

Tip (3): Bu kontroller ürün müşteriye ulaşmadan hatayı ortaya çıkarmaktadır. Müşteri bir sonraki faaliyet, alt faaliyet ya da nihai tüketici olabilir.

Saptanabilirlik : 1 ile 10 derecelendirme yapılır ve ürün henüz üretim hattındayken, hatanın sebep olduğu bir kusuru bulma/görebilme olasılığının tahmin edilmesidir. Hatanın açıkça farkedilebilirliği halinde bu değer 1 olacaktır. 1 değeri verildiğinde müşteriye hatalı ürün gönderme olasılığı çok zayıftır. Müşteriye hatalı ürünü hatayı farketmeden gönderme olasılığı düşük ise bu değer 2-5 arasında alınacaktır. Kolaylıkla tespit edilebilen bir hatanın müșteriye gönderilme olasılığının orta düzeyde olması olasılığı halinde 6-8 değeri verilecektir. Hatanın saptanabilirliği güç ise ve müşteriye bu hata ile gönderilme olasılığı yüksek ise bu değer 9 olacaktır. Hata saptanması çok zor bir hata ise ve müşteriye bu haliyle gönderilme olasılığı çok yüksek ise değer 10 olacaktır.

Risk Öncelik Sayısının Belirlenmesi : Risk öncelik sayısı (RÖS), kritiklik sayısı göstergesidir. RÖS her bir hata türü veya nedeni için şiddet (Ş), oluşum(O), ve saptanabilirlik(S) gibi üç risk faktörü esas alınarak belirlenen sayısal değerdir. Çarpma işlemi ile (RÖS = S x O x S) RÖS değeri bulunur. RÖS değeri yüksek olan hata türleri üstte olmak üzere hatalar siralanır. $\mathrm{Bu}$ siralama, hataların önem sıralamasıdır ve iyileştirme faaliyetleri bu öncelik sıralamasına göre yapılır. Risk öncelik puanının minimum değeri 1 ve maksimum değeri ise 1000'dir.

Uygulamalarda genelde $\mathrm{RÖS} \geq 100$ ise düzeltici ve önleyici faaliyetler uygulamaya konulmaktadır.

\section{TEKSTIL BOYA TERBIYYESINDE İŞLETMESINNDE HTEA UYGULAMASI}

Seçilmiş bir tekstil işletmesinin boya terbiye bölümünde HTEA tekniği uygulanmıştır. HTEA tekniğinin uygulaması, aşağıda verilen sıralamaya göre gerçekleştirilmiştir.

a) HTEA ekibinin oluşturulması: Her işletme için üretim mühendisi, kalite mühendisi, planlama mühendisi, satın alma sorumlusu ve üretim sorumlusunun yer aldığı HTEA ekibi oluşturulmuştur.

b) Problemin Belirlenmesi: Araștırma kapsamındaki işletmede görülen sorunlar önem düzeylerine göre sıralanmış ve öncelikli olarak çözülecek sorunlar belirlenmiştir.

c) Sistem analizi: Çözülecek soruna ait sistemin analizi yapılarak hata türleri, etkileri ve nedenleri belirlenmiştir.

d) Değerlendirme: $\mathrm{Bu}$ aşamada her bir hatanın, şiddet, olasılık, saptanabilirlik ve risk öncelik katsayısının (RÖS) değerleri bulunmuştur.

e) Düzeltici önlemlerin alınması: Sorunun işletme koşullarına uygun çözümleri ortaya konulmuştur.

f) Uygulama ve Kontrol: Soruna ait çözümler uygulanarak sonuçları kontrol edilmiştir. (6 ay sonra bu hatalar yeniden kontrol edilmeli, önlemlerin etkileri incelenmelidir.)

İşletmede çalışmanın yapıldığı süre içerisinde çeşitli araştırmalar sonucu belirlenmiş olan ve üretim prosesini dolaysız veya dolaylı olarak etkileyen faktörler önem sirasina göre Çizelge 1' de gösterilmiştir. 
$\mathrm{Bu}$ araştırma çerçevesinde öncelikli olarak üretim esnasında karşılaşılan hataları azaltmaya yönelik bir çalışma yapılmasına karar verilmiştir. $\mathrm{Bu}$ amaçla Seçilmiş Boya Terbiye Dairesi’nde çeşitli zaman aralıklarında 5 haftada toplam 10 günlük bir araştırma yapıldı. $\mathrm{Bu}$ zaman zarfinda üretim esnasında karşılaşılan hatalar tespit edildi. Çizelge 2' de işletmede tespit edilen başlıca hatalar, metrajları ve toplam hatalara göre oluş yüzdeleri gösterilmiştir. Hatanın yüzdesi toplam üretim içinde hatalı metrajın oranını vermektedir.

Çizelge 1. Boya terbiye işletmesinde hata oluşumunda etken faktörler

\begin{tabular}{|c|l|}
\hline $\begin{array}{c}\text { Önem } \\
\text { Sıras1 }\end{array}$ & \multicolumn{1}{c|}{ Faktörler } \\
\hline 1 & $\begin{array}{l}\text { Üretim Esnasında Karşılaşılan } \\
\text { Hatalar }\end{array}$ \\
\hline 2 & $\begin{array}{l}\text { İsletme İçerisinde Mühendis } \\
\text { Eksikliği }\end{array}$ \\
\hline 3 & $\begin{array}{l}\text { Makine Bakım Onarımına Gerekli } \\
\text { Önemin Verilmemesi }\end{array}$ \\
\hline 4 & $\begin{array}{l}\text { Bölümler Arası İletişimin Zayıf } \\
\text { Olması }\end{array}$ \\
\hline 5 & $\begin{array}{l}\text { Bazı Makinelerden Tam Randıman } \\
\text { Alınamaması }\end{array}$ \\
\hline 6 & Yeterli Sayıda İşçi Çalıştırılmaması \\
\hline 7 & Motivasyon Eksikliği \\
\hline
\end{tabular}

Çizelge 2. Belirlenen boya-terbiye hata türleri ve miktarları

\begin{tabular}{|l|c|c|}
\hline $\begin{array}{c}\text { Hata } \\
\text { Türleri }\end{array}$ & $\begin{array}{c}\text { Hatanın Metrajı } \\
(\mathrm{m})\end{array}$ & $\begin{array}{c}\text { Hatanın } \\
\text { Yüzdesi (\%) }\end{array}$ \\
\hline $\begin{array}{l}\text { Boya } \\
\text { Almama }\end{array}$ & 4292 & 0,047 \\
\hline $\begin{array}{l}\text { Boya } \\
\text { Kırı̆ğ }\end{array}$ & 15514 & 0,170 \\
\hline Yağ-Pas & 15919 & 0,170 \\
\hline Abraj & 393 & 0,004 \\
\hline Kanat & 204 & 0,002 \\
\hline $\begin{array}{l}\text { Mekanik } \\
\text { Kırık }\end{array}$ & 22034 & 0,240 \\
\hline En Fark1 & 923 & 0,010 \\
\hline
\end{tabular}

a) Hata adı : Mekanik Kırık : Kumaşa uygulanan işlemler sırasında kumaşın katlanarak belli bir süre silindirliler arasından katlanmış bir şekilde geçmesi nedeniyle oluşan hata türüdür. $\mathrm{Bu}$ hata kumaşın gevşek olarak makineye beslenmesi ve bu sebepten dolayı yeterince gergin olmayan kumaşın katlanarak silindirler arasından geçmesi ile oluşur. Ramözde giderilme oranı yüksektir. Ancak giderilemediği takdirde kumaş 2. kalite olarak ayrılmaktadır. Bu hatanın önüne geçmek için çalışan işçilerin çok dikkatli olması gerekmektedir. Ayrıca makinelerin bakım-onarımlarının zamanında yapılması ile kumaşın makinenin arızasından dolayı gevşek geçmesinin önüne geçilebilir. 
b) Hata adı : Yağ Pas Lekesi : Kumaş üzerinde makineden veya çevreden yağ, pas lekesinin bulaşmasıdır. Deterjan ve gerekli organik çözücülerin kullanılması ile giderilebilir. Ayrıca ramözde fiske olmadan önce fark edilirse önlenebilmesi mümkündür. Ancak hata ramözde de fark edilmez ve kumaş bu şekilde ramözde işlem görürse üzerinde bulunan yağ, pas lekesinin giderilmesi oldukça zorlaşır. Ramözde fiksaj aşamasından önce kontrol edilmesi gerekir. Bu hatayı önlemek için kumaşların sevkiyatı sırasında veya kumaşın makineye girişinde etrafta bulunan yağ birikintileriyle temas ettirilmemesi gerekmektedir. Bunun yanı sıra eski model makinelerin paslandığını göz önünde bulundurursak bu paslanmış yerlerin kumaşla teması kumaşı lekeler. $\mathrm{Bu}$ nedenle paslanmış makinelerin boyanarak pas lekesinin önüne geçilmesi gerekmektedir.

c) Hata adı: Boya Kırı̆̆ı: Jet boyama makinelerinde kumaşlar halat şeklinde boyanmaktadır. Boyama işlemi sırasında halat şeklinde bulunan kumaşın bazı noktalarına ince bir çizgi boyunca boya nüfuz edemez. Bu şekilde oluşan hatadan olayı kumaşın tekrar boyanması gerekmektedir. $\mathrm{Bu}$ da ek bir işlem olmakta ve maliyeti arttırmaktadır.

\section{SONUÇ}

Tekstil ve hazır giyim sektörü rekabet, değişken yapıdaki müşteri beklentileri, teknolojik değişimlerinin etkisini yoğun olarak yaşamaktadır. Tekstil işletmeleri hız, kalite ve maliyet konusunda hızlı ve doğru karar almak zorundadır. $\mathrm{Bu}$ nedenlerden ötürü modern üretim yönetimi tekniklerinden tekstil sektörüne uygun olanlarının işletmelerde benimsenmesi ve uygulanması gerekmektedir. Pek çok üretim aşamasının olması nedeniyle tekstil entegre bir yönetim anlayışına çok uygundur. Entegre yönetim anlayışı takım çalışmasını gerekli kılmaktadır. Takım çalışması ile işletmenin rekabet ortamındaki performansını yükseltecek tekniklerden olan HTEA' nın tekstil sektöründe uygulanabilecek olduğu bu çalışma ile gösterilmiştir. HTEA süreç sırasında karşılaşılan hataların oluşturacağı zaman/ürün kaybının oluşumunun engellenmesini sağlamak amaciyla uygulanmaktadır. $\mathrm{Bu}$ amacı sağlarken hatanın olası etkileri bir takım çalışması ile ortaya konmaktadır. Kritik etkiye sahip olan hata veya hatalar tespit edilir. Hataları önleme çalışmaları hata ile karşılaşma olasılı̆̆ını azaltır. Önleme faaliyetleri, işletmede daha önce yürütülmeyen, istatistiksel proses kontrol benzeri yeni kontrol mekanizmalarının sürekli iyileşme tekniklerinin uygulanması ve sürdürülmesini sağlayabilir. HTEA çalışması sonucunda karar verilen önleyici faaliyetler ile tekstil işletmelerinin ürün çeşitliliğinden kaynaklanan sorunlar büyük ölçüde giderilebilir.

\section{KAYNAKLAR}

1. Yılmaz B.S., 2000. Hata Türü ve Etki Analizi, Dokuz Eylül Üniversitesi Sosyal Bilimler Enstitüsü Dergisi, Cilt 2, Sayı 4.

2. Yaylalı Ç., 2008. Kalite İyileştirmede Hata Türleri ve Etkileri Analizi ve Bir Üretim Sürecinde Uygulama, Selçuk Üniversitesi Fen Bilimleri Enstitüsü Endüstri Mühendisliği Anabilim Dalı, Bitirme Tezi

3. Yücel Ö., 2007. Failure Mode and Effect Analysis in Clothing Production, Tekstil ve Konfeksiyon No:2, pp: 126-131.

4. Kaewsom P., Rojanarowan N., 2014. The Application of FMEA to Reduce Defective Rate from Broken Filament Defects in the Direct Spin Drawing process, IOSR Journal of Engineering (IOSRJEN), Vol. 04, Issue 05, PP 55-58.

5. Özyazgan V., Engin F. Z., 2013. Fmea Analysis and Applications in Knitting Industry, Tekstil ve Konfeksiyon, Vol. 23, No:3, pp:228-232.

6. Gültekin, .C., 2001. Tekstil Terbiyesinde Pamuklu Materyalin Boyanmasinda Karşılaşılan Hataların Oluş Nedenleri ve Giderilme Yöntemleri, Electronic Journal of Textiles, Vol:2, No:1. 
